\title{
An Outbreak of Pseudomonas stutzeri Bacterial Isolation Caused by Sterile Dressing Products
}

\author{
Min $\mathrm{Choi}^{1}$, Ji Seon Cheon ${ }^{1}$, Woo Young Choi ${ }^{1}$, Kyung Min Son ${ }^{1}$, Jung Suk Ki ${ }^{2}$, Yeon Kim ${ }^{3}$ \\ ${ }^{1}$ Department of Plastic and Reconstructive Surgery, Chosun University College of Medicine, Gwangju; \\ ${ }^{2}$ Department of Nursing, Chosun University Hospital, Gwangju; \\ ${ }^{3}$ Department of Quality Improvement, Chosun University Hospital, Gwangju, Korea
}

\begin{abstract}
Wound dressing aids the recovery of infected or postoperative wounds; however, dressings should be administered using appropriate sterilization methods. Occasionally, soft tissue infections, a common type of healthcare-associated infections (HAls), occur because of specific bacterial isolations that are often attributed to cross-contamination by medical professionals. Here, we report the case of a sudden increase in the incidence of Pseudomonas stutzeri isolation from the wounds of nine patients in the plastic surgery department of our hospital. Samples for bacterial cultures were obtained from various areas in the dressing environment to identify the exact cause. P. stutzeri was isolated from the saline-soaked cotton container. Therefore, the authors eliminated the use of the dressing container and implemented a dressing procedure that administered saline solution on an individual, need-by-need basis. This new method reduced the incidence of $P$. stutzeri. Additionally, $P$. stutzeri was not isolated from the dressing cart or doctor's gown, suggesting that proper sterilization and careful control of the healthcare setting, personnel, and materials can reduce the transmission and incidence of HAls.
\end{abstract}

Keywords: Pseudomonas stutzeri, Healthcare-associated infections, Wound infection

\section{Introduction}

Healthcare-associated infections (HAls) occur in patient care settings, especially in hospital environments. With the rapid increase and widespread proliferation of multidrug-resistant (MDR) bacteria, the control and prevention of HAls remains a challenging health problem. HAls are caused by viral, fungal, and bacterial pathogens, such as Staphylococcus aureus, Pseudomonas aeruginosa, and Pseudomonas stutzeri. P. stutzeri is a nonfluorescent denitrifying bacterium that is widely distributed among diverse ecological niches; however, it has been isolated as an opportunistic human pathogen. ${ }^{1}$ We witnessed an increase in the incidence of $P$. stutzeri isolations from patient wounds across several wards in our medical center. Here, we discuss our observations and share recommendations for the avoidance of increased $P$. stutzeri incidence in hospital settings.

\section{Case}

In the plastic surgery department of our hospital, patients with soft tissue defects are treated with a daily disinfectant regimen, and a bi-weekly wound swab culture is
Case Report

Received: May 15, 2017
Revised: May 25, 2017

Revised: May 25, 2017

Corresponding author:

Ji Seon Cheon, M.D., Ph.D.

Department of Plastic and Reconstructive Surgery, Chosun University College of Medicine, 309 Pimun-daero, Dong-gu,

Gwangju 61452, Korea

Tel: +82-62-220-3180

Fax +82-62-225-0996

E-mail: ps9107@naver.com

No potential conflict of interest relevant to this article was reported.

This is an Open Access article distributed under the terms of the Creative Commons Attribution NonCommercial License (http://creativecommons.org/ licenses/by-nc/4.0/) which permits unrestricted noncommercial use, distribution, and reproduction in any medium, provided the original work is properly cited. C 2017 The Korean Wound Management Society 
performed. After May 2016, the incidence of $P$. stutzeri isolations rapidly increased in patients with soft tissue defects of various body parts. P. stutzeri was isolated from nine patients across three wards. Patient characteristics are presented in Table 1. The majority of the patients' wounds were caused by burns or traumas, with two cases occurring because of postoperative soft tissue defects. All patients underwent wound sterilization treatment performed by a single plastic surgeon in the plastic surgery facility. When an increase in wounds contaminated by P. stutzeri was observed, the authors consulted the Infection Control Department of the hospital. The department hypothesized that the environment, disinfectant method, and medical staff within the plastic surgery facility could be the source of infection. Therefore, an investigation was conducted. The infection control department produced

Table 1. Characteristics of nine hospital patients with wound cultures positive for $P$. stutzeri

\begin{tabular}{cclc}
\hline & Age/Sex & Causes of wound & Locations \\
\hline 1 & $21 / \mathrm{F}$ & Trauma & Ankle \\
2 & $59 / \mathrm{M}$ & Diabetes mellitus & Foot \\
3 & $12 / \mathrm{M}$ & Trauma & Knee \\
4 & $79 / \mathrm{F}$ & Burn & Ankle \\
5 & $45 / \mathrm{M}$ & Trauma & Thigh \\
6 & $60 / \mathrm{M}$ & Burn & Shin \\
7 & $68 / \mathrm{F}$ & Postoperative & Scalp \\
8 & $59 / \mathrm{M}$ & Diabetes mellitus & Foot \\
9 & $69 / \mathrm{F}$ & Postoperative & Scalp \\
\hline
\end{tabular}

cultures using samples obtained from the wound dressing room environment, dressing products, and the doctor's hands and gowns. Sterile cotton swabs containing the samples were streaked across a third of a blood agar plate. We found that $P$. stutzeri was isolated from the saline-soaked cotton dressing container and different strains were isolated from the dressing cart and doctor's gowns (Table 2).

Therefore, since $P$. stutzeri was isolated from the salinesoaked cotton container, the disinfectant was believed to be the cause of the outbreak. After removing the contaminated container, we implemented a procedure to prepare fresh saline-soaked cotton each time a wound dressing was required.

Table 2. Results of bacterial cultures from the dressing procedure

\begin{tabular}{|c|c|c|}
\hline & Contents & Results \\
\hline \multirow[t]{5}{*}{$\begin{array}{l}\text { Dressing environment } \\
\text { and products }\end{array}$} & $\begin{array}{l}\text { Normal saline dressing } \\
\text { container }\end{array}$ & $\begin{array}{l}\text { Pseudomonas stutzeri } \\
\quad \text { (Few) }\end{array}$ \\
\hline & $\begin{array}{l}\text { Potadine dressing } \\
\text { container }\end{array}$ & No growth \\
\hline & Dressing forceps & No growth \\
\hline & Dressing carts & $\begin{array}{l}\text { Gram positive bacilli } \\
\text { (Few) }\end{array}$ \\
\hline & Dressing beds & $\begin{array}{l}\text { Gram positive bacilli } \\
\text { (Few) }\end{array}$ \\
\hline \multirow[t]{2}{*}{ Healthcare team } & Doctor's gowns & $\begin{array}{l}\text { Staphylococcus aureus } \\
\text { (three colonies) }\end{array}$ \\
\hline & Doctor's hands & $\begin{array}{l}\text { Coagulase-negative } \\
\text { staphylococcus (Few) }\end{array}$ \\
\hline
\end{tabular}

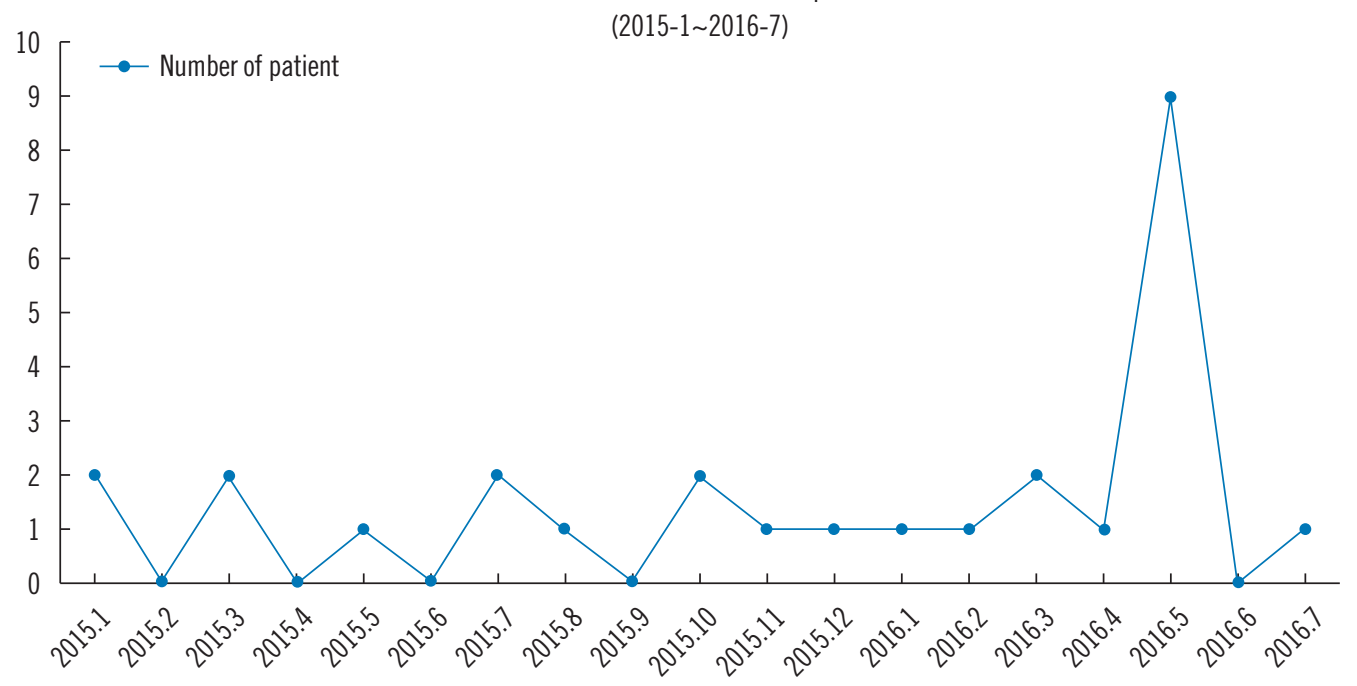

Figure 1. Monthly occurrence of patients with $P$. stutzeri isolation. 
As a result, the incidence of $P$. stutzeri isolations decreased over the next two months (Figure 1).

\section{Discussion}

HAls, also known as nosocomial infections, refer to infections that occur 48 hours after admission to medical institutions such as hospitals, nursing hospitals, and outpatient clinics. ${ }^{2}$ HAls do not include infections in the incubation period at the time of admission. Each year, millions of patients worldwide are affected by HAls. Recently, incidences have been attributed to an increase in immunocompromised patients and the generalization of invasive procedures, both of which often lead to extended periods of hospitalization, thereby increasing the mortality risk and medical expenses. Furthermore, a high incidence of infections are caused by MDR bacteria, such as methicillin-resistant Staphylococcus aureus (MRSA), vancomycin-resistant Staphylococcus aureus, and vancomycin-resistant enterococci. ${ }^{3}$ HAls are commonly caused by MRSA, Acinetobacter baumannii, and Pseudomonas aeruginosa, which can lead to urinary tract infections, postoperative surgical site infections, pneumonia, and soft tissue infections. ${ }^{4}$ Less commonly, HAls have been shown to be caused by $P$. stutzeri, an anaerobic, nonfermenting, active, gram-negative, oxidase-positive bacteria. P. stutzeri rarely induces community-acquired and nosocomial infections, yet HAls caused by $P$. stutzeri involve pneumonia, meningitis, osteomyelitis, prosthetic knee infections, and soft tissue infections. In addition, $P$. stutzeri can lead to severe bacteremia in immunocompromised patients. ${ }^{5}$ Therefore, epidemiologic studies are needed to improve monitoring and control of HAls.

In this case report, the authors witnessed a sudden increase in the number of patients with $P$. stutzeri isolations despite application of the medical institution's standard sterilization protocol. Nine patients had P. stutzeri-infected wounds, with five wounds caused by burns or trauma, two wounds caused by diabetes mellitus, and two wounds caused by postoperative soft tissue defects. For each case, cultures were obtained from the wound dressing room environment and products, including the saline-soaked cotton container, the potadine-soaked cotton container, dressing forceps, dressing carts, and dressing beds, and from the healthcare team, including the doctor's hands and gowns. Results indicated that the strain of $P$. stutzeri originated exclusively from the saline-soaked cotton container. In addition, Gram-positive bacilli were found on the dressing cart and bed, and three colonies of Staphylococcus aureus and coagulase-negative staphylococci were detected on the doctor's gown and hands, respectively. Therefore, the observed HAls were caused by cross-contamination of sterile sites. These findings are supported by the reduction of $P$. stutzeri isolations once the contaminated container was removed and a procedure of preparing fresh dressings as needed was implemented. Our findings lend support to the new strategy implemented to reduce the incidence of HAls.

In the intensive care unit, $40-60 \%$ of HAls are caused by normal flora infections while $20-40 \%$ are caused by cross-infections from medical personnel. ${ }^{6}$ The probability of nosocomial infections has decreased with the application of alcoholbased hand sanitizers and propagation of hand hygiene education. ${ }^{7}$ However, despite wearing personal protective equipment, such as gowns and masks, and practising appropriate hand hygiene, doctors remain a primary conduit of HAls because they are in frequent contact with patients and hospital environments. ${ }^{8}$ This notion is supported by the findings of this case report because bacterial isolations were found on the physician's gown and dressing cart. Therefore, medical institutions should consider infection control strategies to improve sanitization methods and environments.

However, this case report also revealed bacterial isolations in the dressing product, demonstrating the importance of appropriate wound care. Topical antiseptics, such as povidoneiodine, chlorhexidine, alcohol, acetate, hydrogen peroxide, boric acid, and silver nitrate are used in clinical practice. ${ }^{9}$ Normal saline has been used typically for wet dressings because it is cheap and easy to apply, even though the solution has no antiseptic properties. ${ }^{10}$ In this case, P. stutzeri was isolated from the saline-soaked cotton container, even though the solution and dressing were replaced and freshly prepared daily. However, because saline does not disinfect, harmful bacteria can multiply and be transmitted to other patients. Therefore, the authors eliminated the use of the dressing container and implemented a dressing procedure that administered saline solution on an individual, need-by-need basis. This new method eradicated the observed bacterial isolations.

Although bacteria of the same species were detected in the saline-soaked cotton container, a limitation of the present study might be that a single doctor performed the sterilization wound dressings in our case. This factor is significant because the bacterial contamination could have been a product of individual actions rather than institutional procedures. 


\section{Conclusion}

HAls affect millions of patients worldwide, yet they can be controlled with effective strategies and methods. As demonstrated in this case report, proper sterilization and careful control of healthcare settings, personnel, and materials can reduce the transmission and incidence of HAls.

\section{Reference}

1. Bisharat N, Gorlachev T, Keness Y. 10-Years hospital experience in Pseudomonas stutzeri and literature. Open Infect Dis J 2012;6:21-4.

2. Kim YA, Lee H, Lee K. Contamination of the hospital environmental by pathogenic bacteria and infection control. Korean J Nosocomial Infect Control 2015;20:1-6.

3. Kwak YG, Choi JY, Yoo H, et al. Korean National Healthcareassociated Infections Surveillance System, Inten sive Care Unit Module Report: Summary of data from July 2014 through June 2015. Korean J Healthc Assoc Infect Control
Prev 2016;21:37-49.

4. Fournier PE, Richet $\mathrm{H}$. The epidemiology and control of Acinetobacter baumannii in health care facilities. Clin Infect Dis. 2006;42:692-9.

5. Noble RC, Overman SB. Pseudomonas stutzeri infec tion a review of hospital isolates and a review of the literature. Diagn Microbiol Infect Dis 1994;19:51-6.

6. Weinstein RA. Epidemiology and control of nosocomial in fections in adult intensive care units. Am J Med 1991;91: S179-84.

7. Allegranzi $B$, Pittet $D$. Role of hand hygiene in health careassociated infection prevention. J Hosp Infect 2009;73:30515.

8. Huttunen R, Syrjänen J. Healthcare workers as vectors of infectious diseases. Eur J Clin Microbiol Infect Dis 2014;33: 1477-88.

9. Drosou A, Falabella A, Kirsner RS. Antiseptics on wounds: an area of controversy. Wounds 2003;15:149-66.

10. Lim JK, Saliba L, Smith MJ, et al. Normal saline wound dressing-is it really normal normal?. Br J Plast Surg 2000;53:42-5. 